Pawel Zmarzly

\title{
EXPERIMENTAL ASSESSMENT OF INFLUENCE OF THE BALL BEARING RACEWAY CURVATURE RATIO ON THE LEVEL OF VIBRATION
}

Raceway curvature ratio is a very important parameter, because its values influence the performance characteristics of rolling-element bearings, their durability and the level of generated vibrations. However, the level of generated vibrations is one of the most important operating parameters of the rolling-element bearings. Excessive vibrations generated by rolling-element bearings affect the operation of the whole mechanism. The article presents experimental studies aimed at evaluation of influence of the inner and outer raceway curvature ratios of 6304-type rolling-element bearings on generated vibrations values. The raceway curvature ratio was determined based on results of metrological measurements. For this purpose, the radii of the inner and outer raceways as well as the diameters of the balls were measured. Design and principle of operation of an innovative system for analysis of the raceway geometry of the rolling bearing rings was presented. The vibration analysis was carried out in three frequency ranges, i.e. low (50-300 Hz), medium (300-1,800 Hz) and high (1,800-10,000 Hz). Values of measured vibrations were expressed in Anderon units. The test results showed that increase in the raceway curvature ratio causes a moderate decrease in the value of the generated vibrations. The research results presented in this article will serve as a guidance to designers and manufacturers of the rolling-element bearings on how to modify the geometry of raceways and balls to obtain bearings that generate low vibration values. That is very important in car transportation.

Keywords: rolling-element bearings, raceway curvature ratio, vibration, Anderon unit

\author{
Nomenclature \\ $f_{i}$ - bearing curvature ratio for the inner raceway, \\ $f_{o}$ - bearing curvature ratio for the outer raceway, \\ $f_{t}$ - total curvature ratio, \\ $r_{i}$ - radius of inner raceway, \\ $r_{o}$ - radius of outer raceway, \\ $D_{w}$ - ball diameter, \\ $V$ - vibration velocity, \\ $N$ - radian, \\ $N$ - number of octave, \\ $f^{h}$ - the upper limit of the frequency band in $\mathrm{Hz}$, \\ $f$ - the lower limit of the frequency band in $\mathrm{Hz}$, \\ And - Anderon unit.
}

\section{Introduction}

The rolling-element bearings are a large group of mechanical elements involved in torque transmission, while minimizing friction and the rolling resistance. The rolling-element bearings have found application in various branches of industry, as well as transportation [1]. Increasing demands for improved efficiency of equipment and mechanisms, while, at the same time, reducing energy consumption, require the rolling-element bearings to have a long service life, low running noise and low frictional moment [2]. This is particularly important in mechanisms produced using additive technologies [3-4].
The ball bearings are constructed in the following way: rolling elements are placed between the two rings. The ball moves on the surface of the raceway of the rings to minimize friction and rolling resistance [5-6]. Depending on the type and application, the ball bearings can be equipped with raceways with different radii. The contact surface of rolling elements and raceways depends on their mutual geometry. Moreover, the way balls interact with the bearing ring raceway surfaces influences significantly the bearing performance characteristics. The ratio of the radius of the inner raceway $r_{i}$ or outer raceway $r_{o}$ to the diameter of the balls $D_{w}$ is called the raceway curvature ratio.

Pawel Zmarzly

Department of Mechanical Engineering and Metrology, Kielce University of Technology, Poland

E-mail of corresponding author: pzmarzly@tu.kielce.pl 


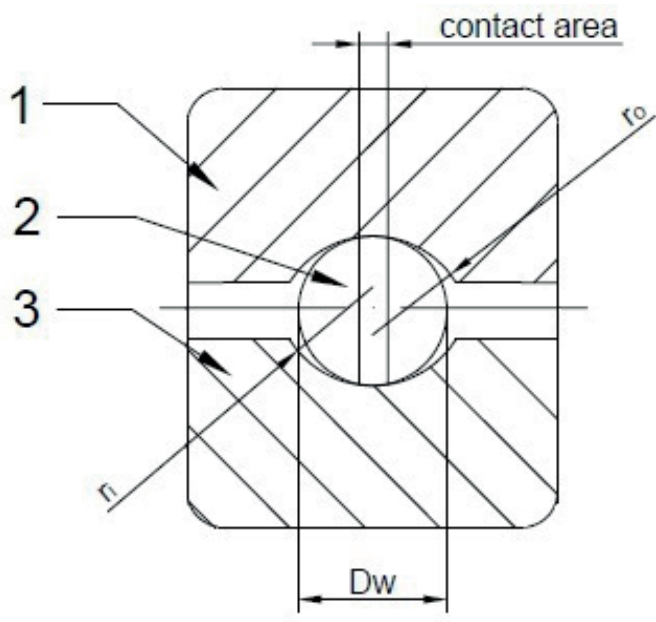

Figure 1 Ball bearing cross-section: 1 - outer ring, 2 - ball, 3 - inner ring

Despite the fact that the raceway curvature ratio is one of the most important design parameters for the ball bearings, there is very little research dedicated to its analysis. In the paper [7], the influence of the raceway curvature ratios of 6203-type ball bearings on the value of frictional moment was studied. Studies have shown that even a small change in the raceway curvature ratio has a significant effect on the frictional moment value. The author of this paper [8] carried out a study to determine how the raceway geometry (described by the raceway curvature ratio) affects the service life of the rolling-element bearings. He demonstrated that reduction of the raceway curvature ratio extends the service life of bearings. Zhu and Haung analyzed the relationship between the contact surface roughness statistical parameters and the bearing ratio curve in [9]. The research made it possible to evaluate how the roughness of slide connections affects the friction and wear of the bearings. The study [10] demonstrated influence of the ball bearing raceway roughness on motions of the balls, skidding, lubrication performance and the stress fluctuation in the substrate. However, the authors did not take the raceway curvature ratios into account. The authors of paper [11] analyzed the phenomena occurring in the contact zone of the balls with raceways in slewing bearings. In addition, they proposed modifications to the raceways of the slewing bearings in order to increase their service life. The paper [12] presents computer models investigating, among others, the influence of rolling element contact mechanic on the moment of friction occurring in slewing bearings. Simulation tests assessing the change in the ball contact zone with the inner raceway of ball bearings due to load changes were presented in [13].

In the first stage of operation of the rolling-element bearings, the friction coefficient depends, among others, on the contact area size and roughness of the cooperating raceway surfaces and rolling elements. Furthermore, excessive friction between the active surfaces of the rollingelement bearings, apart from reducing their service life, also affects values of generated vibrations. Therefore, it can be concluded that the raceway curvature ratios have a direct and indirect influence on values of generated vibrations.
There are many publications describing vibration analysis of rolling-element bearings in terms of their wear [14-15]. There are also many papers which present the influence of various factors on the values of generated vibrations, e.g. roughness or waviness of the raceway [16-18], radial clearance [19-20], raceway defects [21]. However, there are no commonly available studies evaluating influence of the raceway curvature ratios on the generated vibrations. In addition, there are no studies, which describe how the raceway geometry of bearings and balls can be evaluated to determine the raceway curvature ratios. In most cases, the raceway radius is tested using universal measurement systems such as contour measuring instruments or profilometers. However, there is no description of the principle of operation and the construction of specialized systems for analysis of the bearings raceway geometry.

Therefore, experimental testing was conducted to determine the curvature ratios for the inner and outer raceways on new 6304-type rolling-element bearings. Next, the vibration analysis of the tested bearings was carried out and the influence of the raceway curvature ratios on the vibrations generated in specific frequency bands was evaluated. The tests presented in this article will serve as a guidance to designers and manufacturers of the rolling-element bearings on how to modify the geometry of raceways and balls to obtain bearings that generate low vibration values.

\section{Raceway curvature ratio}

The raceway curvature ratio determines the percentage degree of contact (fit) between the ball surface and the raceway surfaces (see Figure 1).

The bearing curvature ratio can be determined for the inner raceway as $f_{i}$, Equation (1), the outer raceway as $\mathrm{f}_{\text {o }}$, Equation (2). The total curvature $f_{t}$, Equation (3) is defined as a sum of curvature ratios determined for the inner and outer raceways:

$f_{i}=\frac{r_{i}}{D_{w}}$ 


\begin{tabular}{|c|c|c|c|c|c|c|c|c|c|}
\hline \multirow{2}{*}{\multicolumn{2}{|c|}{$\odot \mathrm{um} / \mathrm{s} \odot$ Anderons }} & \multirow{2}{*}{\multicolumn{3}{|c|}{$\begin{array}{l}\text { Measurement parameters: } \\
\text { Parameter }\end{array}$}} & \multicolumn{5}{|c|}{ Noise from the bearing element (percentage RMS): } \\
\hline & & & & & $\mathrm{k}$ & Rotations & Outer ring & Iner ring & Ball \\
\hline \multirow{2}{*}{$8.0-$} & & Measurement data & $2017-10-$ & $0: 27$ & fo & $30.0 \mathrm{~Hz}$ & $107.8 \mathrm{~Hz}$ & $162.3 \mathrm{~Hz}$ & $140.6 \mathrm{~Hz}$ \\
\hline & & Number of measurement & N/A07 & & 1 & 9.391 & 1.824 & 1.967 & 1.808 \\
\hline \multirow{4}{*}{$6.0-$} & & Producer & NSK & & 2 & 6.993 & 3.896 & 3.227 & 2.518 \\
\hline & & Bearing symbol & 6304 & & 3 & 6.607 & 3.390 & 3.047 & 2.556 \\
\hline & & Rotation speed & $1801 \mathrm{rpr}$ & & 4 & 8.730 & 3.416 & 4.461 & 5.472 \\
\hline & & Axial load & $60 \mathrm{~N}$ & & 5 & 8.490 & 5.180 & 7.968 & 5.842 \\
\hline \multirow{3}{*}{$4.0-$} & & Recording time & $3.00 \mathrm{~s}$ & & 6 & 2.931 & 5.169 & 4.978 & 6.050 \\
\hline & & \multicolumn{3}{|l|}{ Noise level } & 7 & 4.581 & 6.974 & 1.686 & 4.031 \\
\hline & & Effective value & $\mathrm{um} / \mathrm{s}$ & Anderons & 8 & 5.459 & 8.001 & 1.337 & 2.495 \\
\hline \multirow{5}{*}{$2.0-1$} & & Full bandwidth $(50-10000 \mathrm{~Hz})$ & 56.7 & - & 9 & 2.957 & 5.335 & 0.830 & 1.432 \\
\hline & & Low bandwidth $(50-300 \mathrm{~Hz})$ & 27.9 & 3.6 & 10 & 3.973 & 2.377 & 0.855 & 0.592 \\
\hline & & Medium bandwidth $(300-1800 \mathrm{~Hz})$ & 46.4 & 6.0 & 11 & 3.558 & 1.707 & 0.948 & 1.076 \\
\hline & & High bandwidth $(1800-10000 \mathrm{~Hz})$ & 17.0 & 2.3 & 12 & 3.005 & 1.019 & 0.538 & 0.947 \\
\hline & & Peak & 673.9 & - & 13 & 2.421 & 0.796 & 0.769 & 0.815 \\
\hline
\end{tabular}

Figure 2 Measurement report obtained from Anderonmeter software

$$
\begin{aligned}
& f_{o}=\frac{r_{o}}{D_{w}} \\
& f_{t}=f_{i}+f_{0}-1 .
\end{aligned}
$$

The raceway curvature ratios for most ball bearings fall within the range of $52 \%$ to $58 \%$. As the raceway curvature ratio increases, the contact area between the ball and the raceway decreases. The rolling-element bearings with smaller raceway curvature ratio are suitable for carrying heavier loads. However, too small raceway curvature ratios (less than 50\%) result in excessive ball rolling resistance on the raceway surface, which is detrimental to operation. The rolling-element bearings with high raceway curvature ratios have lower frictional moment. Because of low energy losses, this type of bearing is especially recommended for mechanisms which are activated and stopped repeatedly. It should be added that too high raceway curvature ratios (above 58\%) are also detrimental. In such bearings inner stresses are more frequent, which significantly reduces their service life.

\section{Experimental procedure}

Experimental studies carried out for the purposes of this research were divided into several stages. Fifty new, 6304-type single row ball bearings were used in these studies. The open ball bearings were used in order to eliminate the damping influence of grease on vibration. The research was carried out in Rolling Bearing Laboratory located in Kielce University of Technology.

\subsection{Vibration measurement}

The first step in the study consisted of vibration velocity measurement using the Anderonmeter. A detailed description of the structure and principles of operation of the used measurement system was presented in papers [16] and [22]. The system uses a measuring sensor for vibration velocity. The most significant advantage of using such a sensor is the ability to measure low vibration frequencies, as low as $30 \mathrm{~Hz}$. It should be noted that the low-frequency vibration can be caused, among other things, by incorrect geometry of balls and bearing raceways. Therefore, in terms of assessment of influence of the raceway curvature ratios on the generated vibration values, this range should be analyzed with particular care. The signal from the sensor is amplified, filtered and divided into appropriate frequency bands. The filtration procedure was carried out based on the guidelines presented in the international standard ISO 15242-1. An analogue-digital card PCI-1716L Advantech Company was used to record the measuring signal. Then, the digital wave filter was used for separating oscillations based on their frequency. The band-pass filter has a single transmission band extending from a lower cut-off frequency greater than zero to finite upper cut-off frequency. Signal sampling frequency was $25600 \mathrm{~Hz}$. Number of samples for FFT was 16 384. Using the appropriate software measured signal is filtered and vibrations analysis was carried out for each bearing in three frequency ranges: low (LB) $50-300 \mathrm{~Hz}$, medium (MB) 300-1,800 Hz and high (HB) 1,800 - 10,000 Hz. In order to maintain constant measuring conditions and to meet the standard requirements for vibration analysis, the rolling-element bearings were tested at a constant speed of $1,800 \mathrm{rpm}$. An axial load of $60 \mathrm{~N}$ was used to remove the backlash by means of pneumatic pressure. Fifty rolling ball bearings 6304 types were used for research. Measurement practice has shown that the bearing vibration value changes with the change in the measurement location on the outer ring. Therefore, the vibration was measured at three points distributed evenly at $120^{\circ}$ on the race circumference. The measurements were carried out for two sides of the bearing, which allowed to obtain six sets of results for each bearing. The mean values from the set of results obtained for each bearing were determined for analysis. Figure 2 shows an example of a measurement report obtained from the Anderonmeter system software.

Values of measured vibrations were expressed in Anderon units, which are closely related to the vibration velocity and rotational velocity of the tested rolling-element bearing [16, 23]. An Anderon unit is approximately 7.698 


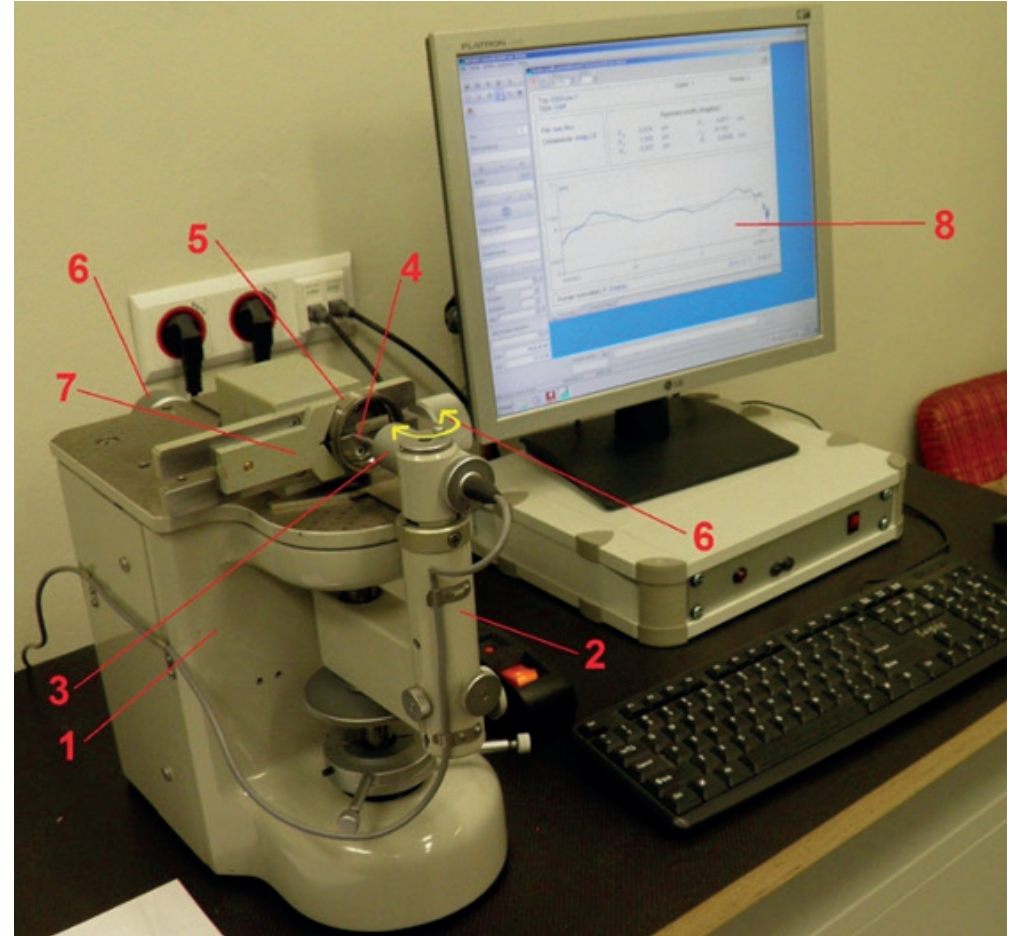

Figure 3 STPP measuring system for analysis of the geometry of bearing raceways:

1 - body, 2 - rotating clamp, 3 - measuring head, 4 - measuring tip, 5 - rolling-element bearing outer ring, 6 - adjustment supports, 7 - magnetic holder, 8 - CYFORM software interface

$\mu \mathrm{m} / \mathrm{s}$. Mathematical interpretation of the Anderon unit is presented in Equation (4):

$$
1 A n d=\frac{V}{n \sqrt{N}}=2 \pi \cdot 30 \sqrt{\log _{2} \frac{f_{h}}{f_{l}}},
$$

where:

$V$ - vibration velocity,

$n$ - radian,

$N$ - number of octave,

$f_{h}$ - the upper limit of the frequency band in $\mathrm{Hz}$,

$f_{l}$ - the lower limit of the frequency band in $\mathrm{Hz}$.

\subsection{Geometry measurement}

After the disassembly of each bearing, the geometry of the inner and outer ring raceways was analyzed, constituting the second stage of the study. The STPP system (Figure 3) developed at the Kielce University of Technology was used to measure the raceway radius.

In addition to measuring the raceway radius, STPP can also be used to analyze the roughness and waviness of bearing raceways. A cast iron body, to which the drive system and measuring system are mounted, is the main element of the instrument. Vertical spindles, mounted in the front part of the body (1), together with the rotating clamp (2) can rotate in $\pm 60^{\circ}$ angle (see yellow arrow in Figure 3 ). The measuring head (3) is mounted at the end of the spindle. By using the plain bearings, the measuring head (3) together with the measuring tip (4) can accurately move along the raceway curve of the bearing ring (5). The correct settings of the measuring tip movement are regulated by the supports (6). For the fast and accurate positioning of the bearing rings to be measured, a magnetic holder (7) is used. The signal from the measuring head is amplified and filtered accordingly. Analysis of the measurement results is performed by the CYFORM software (8).

In most contour measuring stations and profilometers used to analyze the rolling-element bearings raceway geometry, the measuring tip is always perpendicular to the raceway surface and moves along its axis (see Figure 4). Therefore, the measurement is carried out in relation to rectangular coordinates. This can be considered as a simplification and a potential source of errors, as the angle of application of the tip to the raceway surface changes in structures of this type. In addition, when measuring the rounded surfaces, the point of contact of measuring tip with the surface is different each time. In the case of damaged or worn measuring tips, this can have a significant impact on the end result. An example of a rolling-element bearing raceway measurement using the Form Talysurf PGI 1230 profiler is shown in Figure 4.

In the case of the STPP system, measurements were made in polar coordinates along the arc with a defined curvature (radius). The reference radius was set by measuring the standard setting ring before proceeding further. Therefore, the STPP measurement system uses the differential measurement method, i.e. the difference between the actual raceway radius and the standard ring radius is measured at each point. This solution allowed to avoid the complicated calculations, which can result in additional errors. In addition, the tip is always set perpendicular to the raceway curvature, therefore it always measures at a specific point. Due to its compact design, 


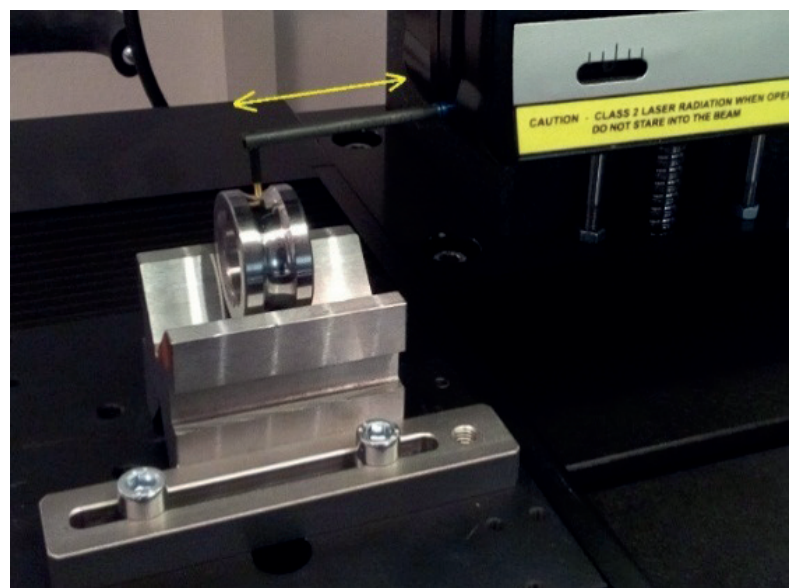

Figure 4 Measurement of radius of the inner ring raceway using the PGI 1230 Form Talysurf system

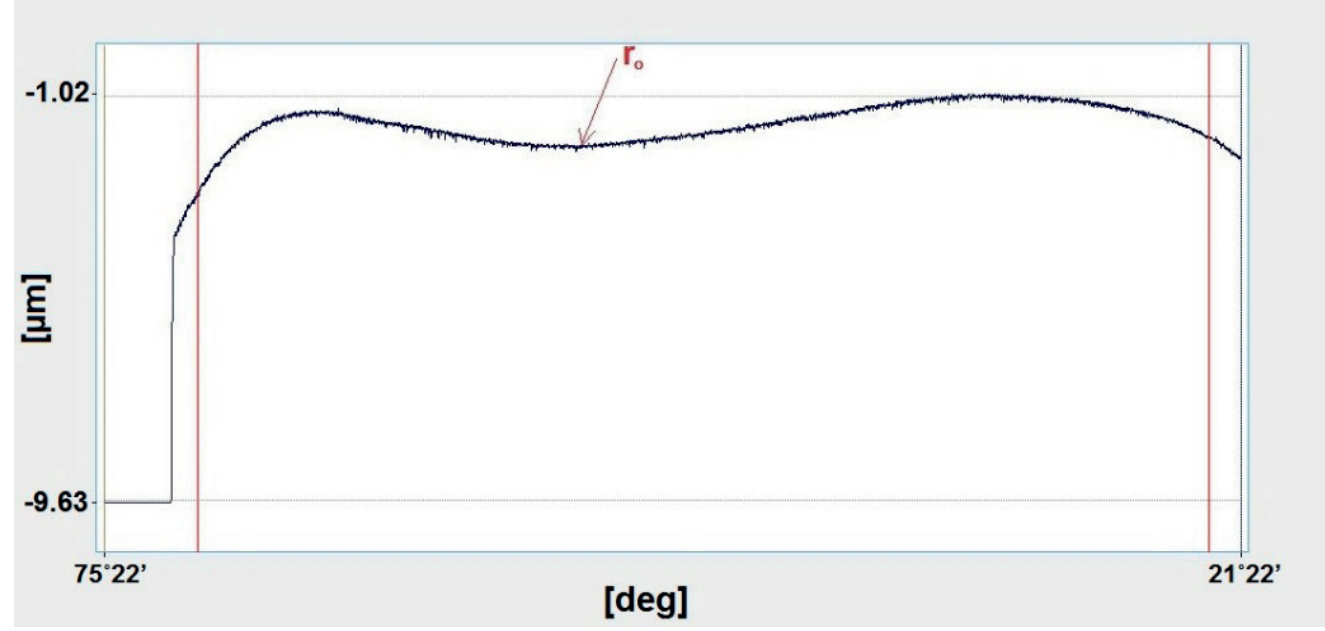

Figure 5 Outer race profile measured using the STPP system

\section{Type: 6304-N-PZ-7}
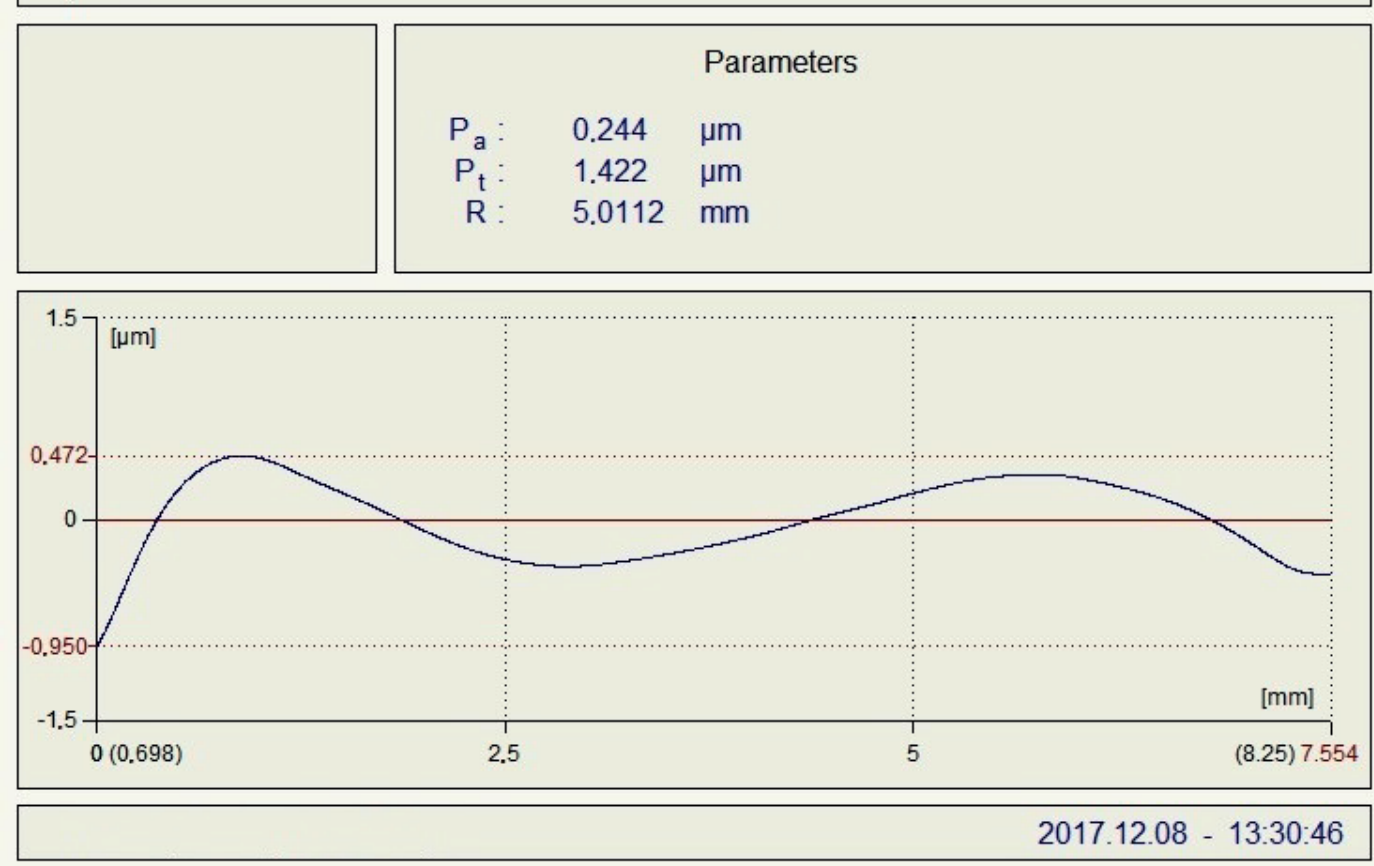

Figure 6 Outer race profile after filtration 
Table 1 Summary of results

\begin{tabular}{|c|c|c|c|c|c|}
\hline & \multicolumn{3}{|c|}{ Vibration values, And } & \multicolumn{2}{|c|}{ Raceway curvature ratio, \% } \\
\hline & $\mathrm{LB}$ & $\mathrm{MB}$ & $\mathrm{HB}$ & $f_{i}$ & $f_{o}$ \\
\hline Numbers of samples & & & 50 & & \\
\hline $\bar{x}$ & 8.81 & 9.10 & 8.53 & 51.85 & 52.73 \\
\hline$x_{\max }$ & 15.37 & 17.53 & 13.93 & 52.79 & 52.96 \\
\hline$x_{\min }$ & 4.52 & 5.12 & 3.33 & 51.54 & 52.40 \\
\hline$R$ & 10.85 & 12.41 & 10.61 & 1.25 & 0.56 \\
\hline$s$ & 2.504 & 2.973 & 2.364 & 0.002 & 0.002 \\
\hline V & 0.284 & 0.327 & 0.277 & 0.00004 & 0.00004 \\
\hline
\end{tabular}

Table 2 Vibrations values calculated for particular selection groups of the rolling-element bearings (for outer raceway curvature ratios $f_{0}$ )

\begin{tabular}{|c|c|c|c|c|c|c|c|}
\hline \multirow{3}{*}{$\begin{array}{c}\text { Selection group } \\
\text { No }\end{array}$} & \multirow{3}{*}{$\begin{array}{l}\text { Range of outer raceway } \\
\text { curvature ratios } f_{0}, \%\end{array}$} & \multicolumn{6}{|c|}{ Vibration values, And } \\
\hline & & \multicolumn{2}{|c|}{$\mathrm{LB}$} & \multicolumn{2}{|c|}{ MB } & \multicolumn{2}{|c|}{$\mathrm{HB}$} \\
\hline & & $\bar{x}$ & $s$ & $\bar{x}$ & $s$ & $\bar{x}$ & $s$ \\
\hline 1 & $<52.40,52.57>$ & 8.47 & 2.46 & 8.18 & 1.89 & 8.52 & 1.12 \\
\hline 2 & $<52.58,52.73>$ & 9.68 & 3.34 & 9.19 & 2.42 & 8.15 & 2.15 \\
\hline 3 & $<52.75,52.80>$ & 8.55 & 1.91 & 9.30 & 3.54 & 8.35 & 2.82 \\
\hline 4 & $<52.81,52.86>$ & 8.42 & 1.61 & 8.42 & 3.18 & 7.77 & 2.48 \\
\hline 5 & $<52.87,52.96>$ & 9.04 & 2.82 & 8.87 & 3.70 & 7.20 & 2.95 \\
\hline
\end{tabular}

the measuring instrument can be used directly in industrial conditions, for example at measuring workstations. Single, precise adjustment of the measuring instrument according to the standard allows for fast and easy measurements, which is particularly desirable in series production such as rolling-element bearings manufacturing. Figure 5 shows an example of the outer race profile measured using the STPP system, while Figure 6 presents the filtered profile together with calculated measurement parameters (radius of the outer race $R=5.0112$ ).

The next step in the study was to measure the diameter of the balls using a horizontal length measuring device KLM 60.01 from Steinmeyer. Based on the measured values, i.e. the radius of the outer and inner raceway and the diameters of the balls, the raceway curvature ratios for the outer and inner raceways were determined.

\section{Results and discussion}

A vibration analysis was carried out for each bearing. Vibration values were determined for three frequency ranges, i.e. low (LB), medium (MB) and high (MB). Then, for each bearing inner raceway $f_{i}$ and outer raceway $f_{o}$ curvature ratios were determined. The group of fifty rolling bearings was examined. Due to the large number of measurement results, Table 1 presents only results of statistical calculations obtained from all the measurement results, i.e. the average value $(\bar{x})$, maximum value $\left(x_{\max }\right)$, minimum value $\left(x_{\min }\right)$, mean squared error $(s)$, range $\left(R=x_{\text {max }}-x_{\text {min }}\right)$, and coefficient of variation $\left(V=\frac{s}{\bar{x}}\right)$.
Analyzing the results presented in Table 1, it can be concluded that the vibration values expressed in Anderon units (And) are characterized by increased variability in comparison to the raceway curvature ratios. However, considering the average values of vibrations in relation to specific frequency ranges (LB, MB, HB), it can be stated that the highest vibrations were recorded in the average frequency range of vibrations, i.e. $300-1,800 \mathrm{~Hz}$. The lowest values were recorded for the high frequency range. However, one can see that the average values were similar for all the analyzed frequency ranges. High values of the mean squared error $(s)$, determined for vibrations values, are indicative of the high variability of the measurement results. This indicates a large discrepancy in values of the vibrations generated by the tested bearing. For the average vibration frequency range, for example, the range was $R=12.41$ And. This is also confirmed by the high values of the coefficient of variation $V$ (see the last row in Table 1). For all the tested frequencies these coefficients were higher than $27 \%$, which proves that the analyzed characteristics are statistically significant and have average variability. However, when considering the static values calculated for the raceway curvature ratios, it can be concluded that the results were more consistent when compared. For both the inside and outside raceway curvature ratios, the mean squared error values were very small ( $s=0.002 \%)$. Coefficients of variation demonstrated that the inner raceway curvature ratios were more differentiated than those of the outer raceway. In addition, it can be stated that the average the outer raceway curvature ratios were higher 
Table 3 Vibrations values calculated for individual selection groups of rolling-element bearings (for inner raceway curvature ratios $f_{i}$ )

\begin{tabular}{|c|c|c|c|c|c|c|c|}
\hline \multirow{3}{*}{$\begin{array}{l}\text { Selection } \\
\text { group No }\end{array}$} & \multirow{3}{*}{$\begin{array}{c}\text { Range of inner raceway } \\
\text { curvature ratios } f_{i}, \%\end{array}$} & \multicolumn{6}{|c|}{ Vibration values, And } \\
\hline & & \multicolumn{2}{|c|}{ LB } & \multicolumn{2}{|c|}{$\mathrm{MB}$} & \multicolumn{2}{|c|}{$\mathrm{HB}$} \\
\hline & & $\bar{x}$ & $s$ & $\bar{x}$ & $s$ & $\bar{x}$ & $s$ \\
\hline 1 & $<51.54,51.62>$ & 8.24 & 2.09 & 8.89 & 2.73 & 9.80 & 2.59 \\
\hline 2 & $<51.66,51.78>$ & 8.77 & 2.86 & 9.51 & 2.68 & 9.21 & 2.06 \\
\hline 3 & $<51.79,51.89>$ & 9.22 & 3.37 & 8.61 & 3.72 & 8.75 & 1.98 \\
\hline 4 & $<51.92,52.01>$ & 9.22 & 2.43 & 9.22 & 3.27 & 8.20 & 2.83 \\
\hline 5 & $<52.05,52.79>$ & 8.48 & 1.46 & 9.47 & 3.08 & 7.71 & 2.76 \\
\hline
\end{tabular}

than those of the inner raceway. However, these values are very close $\left(f_{i}=51.85 \%, f_{o}=52.73 \%\right)$.

Due to the very small spread (variability) of raceway curvature ratios and in order to simplify analysis of influence of the raceway curvature ratios on values of the generated vibrations, the tested bearings were divided into 5 selection groups. In each group, ten bearings were analyzed. The divisions were made according to the obtained curvature ratios of the outer raceway $f_{o}$ (see Table 2) and inner raceway $f_{i}$ (see Table 3 ). For each selection group the average vibration values measured for the rolling-element bearings in a given selection group were calculated.

By analyzing the test results presented in Table 2, it can be concluded that an increase in curvature ratios $f_{0}$ determined for the outer raceway, results in a slight increase in the vibration values for low and medium frequencies. Looking at the results presented in Table 2, an increase in the outer raceway curvature ratios in the $f_{o} \in<52.40 \%, 52.80 \%>$ (selection groups 1 to 3 ) causes a rapid increase in the vibrations recorded in the medium range of the $\mathrm{MB}$ vibration frequency. Then a decrease in the vibration values was observed. The situation is similar for the HB high frequency vibration range, where the increase in the raceway curvature ratio after the initial increase in vibration values from 2 to 3 selection group, causes a decrease in vibrations for the 3-5 selection group.

Analyzing the research results presented in Table 3, one can see that the increase in the inner raceway curvature ratio $f_{i}$ causes a moderate increase in the value of generated vibrations recorded in the low (LB) and medium (MB) frequency range. However, by analyzing the vibrations tested in the high frequency range (HB), a downward trend was observed, with an increase in the inner raceway curvature ratios. Nonetheless, similarly to the results obtained for the $f_{o}$, the initial increase in vibrations values is followed by a downward trend. It should be added that as the value of the curvatures ratios increases, the contact area of the ball with the raceways surface decreases. Then the rolling resistance decreases, which may result in a decrease in the value of generated vibrations. In addition, by analyzing the average values and standard deviations obtained for vibration values (see Table 3), one can see that these values are similar to each other for each frequency bands. This means that examined bearings types 6304 do not have significant manufacturing defects.

\section{Conclusions}

In the case of precise and important machine parts, proper operation of the rolling-element bearings is a critical factor that often affects the condition of entire devices or mechanisms. In many cases, manufacturers do not provide detailed information about the operating parameters of rolling-element bearings, such as vibration values, frictional moment values or the raceway curvature ratios. The rollingelement bearings of the same type can have considerably different parameters. It should be added that the values of generated vibrations are the basic parameter describing the technical conditions of new and used bearing assemblies. Excessive vibration values may indicate bearing defects, but they may also result from their design characteristics, e.g. the geometry of raceway and balls. Therefore, the article analyzes influence of the raceway curvature ratios on values of generated vibrations.

The tests presented in the paper demonstrated that the outer raceway curvature ratios reached higher values than those of the inner raceway. However, the results are very close, and for the analyzed bearings the values of the raceway curvature ratios did not exceed 53\%. This type of bearings is designed to carry heavier loads, however, the frictional moment can be higher, which can directly influence values of generated vibrations. Vibration analysis showed that the highest values of vibrations were recorded for the average $\mathrm{MB}$ frequency range of vibrations, i.e. $300-1,000 \mathrm{~Hz}$. However, the vibrations results for all the analyzed frequencies were characterized by a large discrepancy, which may indicate manufacturing defects, especially in light of the fact that the new rolling-element bearings were used in the tests. An increase in both outer and inner curvature ratios causes an initial increase in vibrations values and then their decrease. The only exception is in the high frequency band, where an increase in the inner raceway curvature ratio resulted in decreased vibrations. By analyzing the test results, it can be stated 
that with an increase of the raceway curvature ratio the coefficient of friction between the raceways and the rolling element decreases, which in turn may cause a decrease in the vibrations value.

Besides, it should be added that the vibrations values recorded in the low and medium frequency range depend, among others, on shape errors in the balls and raceways, lubricant contamination or incorrect assembly. Therefore, when examining the effect of the values of raceway curvature ratio on values of generated vibrations that were analyzed in the frequency range $50-1800 \mathrm{~Hz}$ it should be consider the impact of these factors on the final measurement result.

However, the vibrations values analyzed in the high frequency ranges, i.e. above $1800 \mathrm{~Hz}$, result from the bearing operation characteristics. Therefore, this frequency range should be analyzed in details in terms of assessing the impact of the bearing curvature ratio value on the generated vibrations values.

The research results presented in the paper provide some guidelines for manufacturers of low-noise rolling bearings that it is recommended to design the rolling bearings with higher values of the curvature ratio, as this reduces the values of generated vibrations and reduces the rolling resistance.

The studies presented in the article are preliminary for a broader assessment of the influence of selected factors on the level of generated vibrations. It should be noted that the tested bearings were obtained directly from the manufacturer, so the raceway curvature ratios were in the narrow range of $51.54 \%$ to $52.96 \%$. In further research, the author will examine bearings with a broader range of raceway curvature ratio. Other types of bearings will undergo testing, as well. The results presented in this article will be used to develop mathematical models allowing for the assessment of influence of selected factors on values of vibrations generated by the ball bearings.

\section{Acknowledgements}

The research presented in this paper was supported by the National Science Centre of Poland under the scientific work No. 2017/01/X/ST2/00155.

\section{References}

[1] FOMIN, O., GERLICI, J., LOVSKA, A., KRAVCHENKO, K., PROKOPENKO, P., FOMINA, A., HAUSER, V. Durability determination of the bearing structure of an open freight wagon body made of round pipes during its transportation on the railway ferry. Communications - Scientific Letters of the University of Zilina [online]. 2019, 21(1), p. 28-34. ISSN 1335-4205, eISSN 2585-7878. Available from: http://komunikacie.uniza.sk/index.php/communications/article/ view/1164

[2] OLABARRIETA, E., KONDE, E., GURUCETA, E., ARMENDIA, M. New approach for bearing life cycle control. Procedia Manufacturing [online]. 2018, 19, p. 58-65. ISSN 2351-9789. Available from: https://doi.org/10.1016/j.promfg.2018.01.009

[3] ZMARZLY, P., KOZIOR, T., GOGOLEWSKI, D. Dimensional and shape accuracy of foundry patterns fabricated through photo-curing. Tehnicki Vjesnik [online]. 2019, 26(6), p. 1576-1584. ISSN 1330-3651, eISSN 1848-6339. Available from: https://doi.org/10.17559/TV-20181109115954

[4] KOZIOR, T., TRABELSI, M., MAMUN, A., SABANTINA, L., EHRMANN, A. Stabilization of electrospun nanofiber mats used for filters by 3D printing. Polymers [online]. 2019, 11(10), p. 1-11. ISSN 2073-4360. Available from: https://doi.org/10.3390/polym11101618

[5] KOSMOL, J. Analytical determination of rolling friction coefficient of angular bearings. Journal of Manufacturing Science and Engineering [online]. 2017, 140(2), 021002. ISSN 1087-1357, eISSN1528-8935. Available from: https://doi.org/10.1115/1.4037230

[6] SMOLNICKI, T., PEKALSKI, G., JAKUBIK, J., HARNATKIEWICZ, P. Investigation into wear mechanisms of the bearing raceway used in bucket wheel excavators. Archives of Civil and Mechanical Engineering [online]. 2017, 17(1), p. 1-8. ISSN 1644-9665. Available from: https://doi.org/10.1016/j.acme.2016.07.008

[7] GORYCKI, L., ADAMCZAK, S., MAKIELA, W., WRZOCHAL, M. Investigation the influence of the curvature ratio on the frictional moment in rolling bearings. Procedia Engineering [online]. 2017, 192, p. 255-258. ISSN 1877-7058. Available from: https://doi.org/10.1016/j.proeng.2017.06.044

[8] KACZOR, J. The influence of the shape of races for the ball bearings on the life of bearings. Tribologia. 2013, 251(5), p. 33-44. ISSN 0208-7774, eISSN1732-422X.

[9] ZHU, S., HUANG, P. Influence mechanism of morphological parameters on tribological behaviors based on bearing ratio curve. Tribology International [online]. 2017, 109, p. 10-18. ISSN 0301-679X. Available from: https://doi.org/10.1016/j. triboint.2016.12.014

[10] YUNLONG, W., WENZHONG, W., SHENGGUANG, Z., ZIQIANG, Z. Effects of raceway surface roughness in an angular contact ball bearing. Mechanism and Machine Theory [online]. 2018, 121, p. 198-212. ISSN 0094-114X. Available from:https://doi.org/10.1016/j.mechmachtheory.2017.10.016 
[11] KANIA, L., PYTLARZ, R., SPIEWAK, S. Modification of the raceway profile of a single-row ball slewing bearing. Mechanism and Machine Theory [online]. 2018, 128, p.1-15. ISSN 0094-114X. Available from: https://doi.org/10.1016/j. mechmachtheory.2018.05.009

[12] HERAS, I., AGUIRREBEITIA, J., ABASOLO, M., PLAZA, J. Friction torque in four-point contact slewing bearings: Applicability and limitations of current analytical formulations. Tribology International [online]. 2017, 115, p. 59-69. ISSN 0301-679X. Available from: https://doi.org/10.1016/j.triboint.2017.05.011

[13] ANOOPNATH, P. R., SURESH BABU, V., VISHWANATH, A. K. Hertz contact stress of deep groove ball bearing. Materials Today: Proceedings [online]. 2018, 5(2/1), p. 3283-3288. ISSN 2214-7853. Available from: https://doi.org/10.1016/j. matpr.2017.11.570

[14] ZHENG, J. Rolling bearing fault diagnosis based on partially ensemble empirical mode decomposition and variable predictive model-based class discrimination. Archives of Civil and Mechanical Engineering [online]. 2016, 16, p.784-794. ISSN 1644-9665. Available from: https://doi.org/10.1016/j.acme.2016.05.003

[15] LI, W., QIU, M., ZHU, Z., WU, B., ZHOU, G. Bearing fault diagnosis based on spectrum images of vibration signals. Measurement Science and Technology [online]. 2016, 27(3), p. 1-11. ISSN 0957-0233. Available from: https://doi.org/10.1088/0957-0233/27/3/035005

[16] ADAMCZAK, S., ZMARZLY, P. Influence of raceway waviness on the level of vibration in rolling-element bearings. Bulletin of the Polish Academy of SciencesTechnical Sciences [online]. 2017, 65(4), p. 541-551. ISSN 2300-1917. Available from: https://doi.org/10.1515/bpasts-2017-0059

[17] CUI, S., GU, L., FILLON, M., WANG, L., ZHANG, C. The effects of surface roughness on the transient characteristics of hydrodynamic cylindrical bearings during startup. Tribology International [online]. 2018, 128, p. 421-428. ISSN 0301-679X. Available from: https://doi.org/10.1016/j.triboint.2018.06.010

[18] ADAMCZAK, S., ZMARZLY, P., STEPIEN, K. Identification and analysis of optimal method parameters of the V-block waviness measurements. Bulletin of the Polish Academy of SciencesTechnical Sciences [online]. 2016, 64, p. 325-332. ISSN 2300-1917. Available from: https://doi.org/10.1515/bpasts-2016-0037

[19] XI, S., CAO, H., CHEN, X., NIU, L. A dynamic modeling approach for spindle bearing system supported by both angular contact ball bearing and floating displacement bearing. Journal of Manufacturing Science and Engineering [online]. 2017, 140(2), 021014. ISSN 1087-1357, eISSN1528-8935. Available from:https://doi.org/10.1115/1.4038687

[20] ZMARZLY, P. Influence of the internal clearance of ball bearings on the vibration level. In: 24th International Conference Engineering Mechanics 2018 : proceedings [online]. Vol. 24. 2018. FISCHER, C., NAPRSTEK, J (ed.). ISBN 978-80-8624688-8, eISBN978-80-86246-91-8, ISSN 1805-8248, eISSN1805-8256, p. 961-964. Available from:https://doi.org/10.21495/91-8961

[21] EL-THALJI, I., JANTUNEN, E. Fault analysis of the wear fault development in rolling bearings. Engineering Failure Analysis [online]. 2015, 57, p.470-482. Available from: https://doi.org/10.1016/j.engfailanal.2015.08.013

[22] ADAMCZAK, S., DOMAGALSKI, R., SENDER, E., ZMARZLY, P., GORYCKI, L. Research methods and testing stand developed to examine vibrations generated by rolling bearing. Diagnostyka [online]. 2016, 17(1), p.41-49. ISSN 16416414, eISSN 2449-5220. Available from: https://www.scopus.com/inward/record.uri?eid=2-s2.0-84973570692\&partnerID $=40 \& \mathrm{md} 5=6 \mathrm{f} 85 \mathrm{a} 706 \mathrm{f} 15 \mathrm{cb} 75 \mathrm{~b} 6 \mathrm{e} 8 \mathrm{eef} 8237 \mathrm{a} 7 \mathrm{~b} 3 \mathrm{ba}$

[23] ADAMCZAK, S., STEPIEN, K., WRZOCHAL, M. Comparative study of measurement systems used to evaluate vibrations of rolling bearings. Procedia Engineering [online]. 2017, 192, p. 971-975. ISSN 1877-7058. Available from: https://doi.org/10.1016/j.proeng.2017.06.167 